\title{
3 Research Square \\ The Effect of Covid -19 Pandemic On Eye-Related Emergency Department Visits: A Comparison of Tertiary Eye Care Hospital Two -Year Results
}

Mevlüt Yılmaz ( $\nabla$ drmevlutyilmaz@gmail.com )

SBU Ulucanlar Eye Training and Research Hospital: SBU Ulucanlar Goz Egitim Ve Arastirma Hastanesi https://orcid.org/0000-0001-7896-7279

\section{Kubra Serbest Ceylanoglu}

Ankara Ulucanlar Eye Training and Research Hospital: SBU Ulucanlar Goz Egitim Ve Arastirma Hastanesi

\section{Emine Malkoc Sen}

SBU Ulucanlar Eye Training and Research Hospital: SBU Ulucanlar Goz Egitim Ve Arastirma Hastanesi

\section{Research Article}

Keywords: COVID 19, emergency department, eye, pandemic

Posted Date: December 21st, 2021

DOI: https://doi.org/10.21203/rs.3.rs-1183403/v1

License: (a) This work is licensed under a Creative Commons Attribution 4.0 International License. Read Full License

Version of Record: A version of this preprint was published at Beyoglu Eye Journal on August 5th, 2022. See the published version at https://doi.org/10.14744/bej.2022.58966. 


\section{Abstract}

Purpose: The aim of study is to examine the clinical and demographic impact of the Covid 19 pandemic on emergency department admissions to a tertiary eye care hospital.

Methods: Records of admissions to the ophthalmology emergency department during a one-year period before the pandemic (group 1) and during the pandemic (group 2) were retrospectively reviewed between March 15, 2019, and March 15, 2021. Application numbers, demographic characteristics of patients were recorded. The cases were grouped by age and diagnosis, and the findings were compared within and between the groups.

Results: A total of 161941 patients (Group 1: 103178 and Group 2: 58 763) were admitted to the emergency department of our hospital within 2 years. All admission diagnoses were significantly lower in the pandemic period than in the pre-pandemic period ( $p: 0.001)$. However, the rate of sight-threatening cases or cases requiring urgent treatment (retinal diseases, uveitis, etc.) was significantly higher in the pandemic period than in the pre-pandemic period ( $\mathrm{p}: 0.001$ ). The most common admission diagnoses were ocular infectious/inflammatory diseases while the foreign body on the ocular surface/ocular trauma group was second. Admissions for allergic and infectious diseases were significantly less during the pandemic period ( $\mathrm{p}: 0.001, \mathrm{p}: 0.002$ respectively).

Conclusion: The Covid 19 pandemic has led to significant changes in the application numbers, demographic features and reasons for admissions to the emergency department.

\section{Introduction}

The Coronavirus-2019 (Covid-19) pandemic has led to major changes in healthcare services as well as the social and economic changes it has caused worldwide [1]. From March 11, 2020 the day when the first Covid-19 case occurred in Turkey, serious measures such as quarantine, curfews, and travel bans have been imposed to prevent the spread of the disease throughout the country, especially in major cities. Furthermore, additional measures such as working from home have been encouraged in areas where this is possible. Frontal teaching in schools has been suspended and distance education has been started [2].

Measures have been taken by the Turkish Ministry of Health, such as ordering health services to give priority to emergency patients, postponement of elective surgeries, and serving only patients with appointments in outpatient clinics [3]. From the beginning of the pandemic period, the Turkish Ophthalmology Association organized online meetings about what to look out for in this process, determined the types of surgeries considered urgent, and published comprehensive guidelines on the management of various ocular diseases [4]. During this period telemedicine services and online video consultations, which allow patients to be examined remotely without coming to the hospital have been increasingly used in many hospitals in our country and around the world [5-7]. Hospitalization also decreased significantly during this time and outpatient follow-up and treatment were scheduled whenever possible [8]. In addition, the public was urged not to go to hospitals in non-emergency situations [3]. 
All kinds of health service presentations, from outpatient examination to medical and surgical treatment, were severely affected during the pandemic period [9]. During this period it was reported that ophthalmic patients do not have sufficient access to health care delivery and both medical and surgical treatment services are negatively affected $[10,11]$. On the other hand, positive effects were also observed during this period; for example, eye trauma was reported to be significantly lower during this period [12] and the incidence of contagious eye infections decreased thanks to strict closure policies and greater adherence to hygiene rules and social distance[11]. It has even been reported that the incidence of retinal detachments is lower during the pandemic period[13].

The Covid 19 pandemic has led to individual behavioral changes worldwide [14]. A study by Shiraly et al. [15] reported that people had less hand-to-face contact during the pandemic period and were more likely to avoid touching mucosal surfaces such as the mouth, nose, and eyes. Also, considering that the use of contact lenses $(\mathrm{CL})$ increases the risk of contracting Covid-19, it was found that the number of people using $C L$ decreased, and the wearing time of $C L$ users was shortened $[16,17]$.

Our study aims to show how the number of patient admissions and admission diagnoses in the emergency department of a tertiary eye hospital were affected by the Covid 19 pandemic.

\section{Method}

Approval was obtained from the local ethics committee for the study (Ankara Training and Research Hospital Ethics Committee, number:2021-647) and the study was conducted in accordance with the principles of the Declaration of Helsinki. The records of registrations in the emergency department of our hospital between March 15, 2019 and March 15, 2021 were retrospectively analyzed from the electronic database of our hospital. Patients were divided into a total of 8 groups according to the date range. Group 1 Spring period: March 15 - June 15 (n: 28 871); Group 1 Summer period: June 15 - September 15 (n: 26 232); Group 1 Autumn period: September 15 - December 15 (n: 24 245); Group 1 Winter period: December 15, 2019- March 15, 2020 (n: 23 830); Group 22020 Spring period: March 15 - June 15 (n: 14 275); Group 2 Summer period: June 15 - September 15 (n: 20 371); Group 2 Autumn period: September 15 - December 15 (n: 13 491); Group 2 Winter period: December 152020 - March 15, 2021 (n: 10 616).

Our hospital is a tertiary eye care hospital where only eye diseases are evaluated. For this reason, only patients with eye emergency are admitted to our hospital's eye emergency department. It is open 365 days / 24 hours and patients presenting with elective complaints such as a refractive examination are not admitted to the emergency department.

In the emergency department, the visual acuity was evaluated with a Snellen chart, and biomicroscopic anterior segment and fundus examinations of the patients were performed. Additional ocular imaging and laboratory tests were ordered where necessary. The diagnoses given to the patients were retrospectively evaluated, one by one, by the hospital information management system, and the preliminary diagnoses were grouped and the disease that was the reason for coming to the emergency room was accepted as the main diagnosis. For each patient, one diagnosis was included in the study. 
Diagnoses other than the main diagnosis, such as secondary glaucoma and dry eye, were not included in the study.

\section{Statistical Analysis}

Statistical analyzes were performed using Statistical Package for Social Sciences version 25.0 software for Windows (IBM SPSS Statistics for Windows. version 25.0. Armonk. NY: IBM Corp.. USA). Explanatory statistics of variables were reported as mean \pm standard deviation and number (\%). For the univariate analyzes of the variables, the independent t-test and the Chi-Square test were used depending on the type of variables and the availability of the assumptions. In all statistical analyses, cases with a $P$ value less than 0.05 were interpreted as statistically significant.

\section{Results}

The mean age of the 161941 patients who participated in the study during the entire study period was $36.45 \pm 19.02$ years. The mean age of patients who arrived during the pandemic period $(37.19 \pm 17.60$ years) was higher than before the pandemic $(36.06 \pm 19.72$ years $)(p=0.001)$. The number of patients admitted in the pre-pandemic period (103 178) was significantly higher than the number of patients admitted in the same post-pandemic period ( $\mathrm{n}: 58$ 763) (p:0.0001). The number of patients admitted to the emergency department within one year of the pandemic outbreak decreased by $43.05 \%$ compared to the same pre-pandemic period (Table 1., p:0.0001).

Table 1

Distribution of the number of patients according to the seasons

\begin{tabular}{|lllll|}
\hline Period & $\mathbf{n}(\%)$ & Group 1 & Group 2 & P* \\
\cline { 1 - 4 } Spring & $43146(100)$ & $28871(66.91)$ & $14275(33.09)$ & \multirow{2}{*}{0.001} \\
Summer & $46603(100)$ & $26232(56.29)$ & $20371(43.71)$ & \\
\cline { 1 - 3 } & $37736(100)$ & $24245(64.25)$ & $13491(35.75)$ & \\
Winter & $34456(100)$ & $23830(69.18)$ & $10626(30.82)$ & \\
Total & $161941(100)$ & $103178(63.71)$ & $58763(36.29)$ & \\
\cline { 1 - 3 } n: number of patients, ${ }^{*}$ Chi-Square test & & \\
\hline
\end{tabular}

Table 1 shows the total number of patients who visited the emergency department by season before the pandemic and during the same period during the pandemic. The number of patients admitted in all seasons decreased significantly during the pandemic period. In terms of the number of patients coming in both periods, during the pandemic period; it was found that the most significant decrease in the number of applications to the emergency service are the spring months with $51.01 \%$ and although there is a decrease in the summer months, it is less than other seasons (22.34\%) (p:0.0001). In the prepandemic period, the season when the highest number of cases reported to the eye emergency room was 
spring, and it was observed that the number of cases gradually decreased from spring to winter. In the pandemic period. the season when the highest number of cases reported to the eye emergency room was summer, and an increase was observed from spring to summer, and after summer, a decrease in the number of cases was observed toward autumn and winter (Table 1).

In the age group of children; more boys than girls presented to the eye emergency department. In the age groups 17-40 years and 41-64 years, the male to female ratio was approximately $2 / 1$ in both groups $(1,73$ and 2,08 in Group 1 and Group 2, respectively). There was no significant difference between females and males in the patients 65 years of age and over (Table 2). The highest number of admissions; both in Group 1 and Group 2, were in the age groups 17-40 and 41-64, respectively. In Group 2, the rates of hospital admissions were lower in the age groups $0-16$ and 65 and older ( $12.9 \%$ and $5.9 \%$, respectively) than in Group 1 (19.5\% and 8\%, respectively). The distribution of patients by Group 1 and Group 2 diagnoses is shown in Table 3. According to these results, a significant decrease was observed in all diagnoses during the pandemic period ( $p: 0.0001$ ). The most common and less frequent diagnoses compared to age groups were shown in figure 1 and figure 2 . 
Table 2

Distribution of eye emergency department admissions according to age and sex in Group 1 and 2

\begin{tabular}{|c|c|c|c|}
\hline \multirow[t]{2}{*}{ Age } & Group 1 & Group 2 & \multirow[t]{2}{*}{$P^{*}$} \\
\hline & n (\%) & n (\%) & \\
\hline \multicolumn{4}{|l|}{0 - 16 years } \\
\hline Female & $8944(44.4)$ & 3085 (40.6) & \multirow[t]{3}{*}{0.001} \\
\hline Male & 11205 (55.6) & 4506 (59.4) & \\
\hline Total & 20149 (100) & 7591 (100) & \\
\hline \multicolumn{3}{|l|}{17 - 40 years } & \multirow[t]{4}{*}{0.001} \\
\hline Female & $12753(33.7)$ & 7129 (29.4) & \\
\hline Male & $25070(66.3)$ & 17136 (70.6) & \\
\hline Total & $37823(100)$ & 24265 (100) & \\
\hline \multicolumn{3}{|l|}{41 - 64 years } & \multirow[t]{4}{*}{0.001} \\
\hline Female & 12254 (33.2) & 7180 (30.7) & \\
\hline Male & $24702(66.8)$ & 16233 (69.3) & \\
\hline Total & $36956(100)$ & $23413(100)$ & \\
\hline \multicolumn{3}{|l|}{$\geq 65$ years } & \multirow[t]{4}{*}{0.51} \\
\hline Female & $3893(47.2)$ & 1672 (47.8) & \\
\hline Male & $4357(52.8)$ & $1822(52.2)$ & \\
\hline Total & $8250(100)$ & $3494(100)$ & \\
\hline \multicolumn{4}{|l|}{ All patients } \\
\hline Female & 37844 (36.7) & 19066 (32.4) & 0,001 \\
\hline Male & 65334 (63.3) & 39697 (67.6) & \\
\hline Total & 103178 (100) & $58763(100)$ & \\
\hline
\end{tabular}


Table 3

Number of patients according to diagnosis in Group1 and 2

\begin{tabular}{|c|c|c|c|c|c|}
\hline \multirow[t]{2}{*}{ Diagnosis } & & \multirow{2}{*}{$\begin{array}{l}\text { Group } 1 \\
n,(\%)\end{array}$} & \multirow{2}{*}{$\begin{array}{l}\text { Group } 2 \\
n,(\%)\end{array}$} & \multirow{2}{*}{$\begin{array}{l}\text { Group 2/Group } \\
1(\%)\end{array}$} & \multirow{2}{*}{$\begin{array}{l}\mathbf{p} \\
\text { (group1- }\end{array}$} \\
\hline & & & & & \\
\hline \multirow{8}{*}{$\begin{array}{l}\text { Infectious/ } \\
\text { Inflammatory }\end{array}$} & - Acute conjunctivitis & $\begin{array}{l}47754 \\
(4628)\end{array}$ & $\begin{array}{l}21974 \\
(3739)\end{array}$ & 46.01 & 0,0001 \\
\hline & - Iridocyclitis & $\begin{array}{l}4154 \\
(4.02)\end{array}$ & $\begin{array}{l}3059 \\
(5.21)\end{array}$ & 73.64 & \\
\hline & $\begin{array}{l}\text { - Adenoviral } \\
\text { Keratoconjunctivitis }\end{array}$ & $\begin{array}{l}2077 \\
(2.01)\end{array}$ & $515(0.88)$ & 24.80 & \\
\hline & - Keratitis & $907(0.88)$ & $450(0.77)$ & 49.61 & \\
\hline & $\begin{array}{l}\text { - Herpetic } \\
\text { keratoconjuctivitis }\end{array}$ & $768(0.74)$ & $470(0.8)$ & 61.20 & \\
\hline & $\begin{array}{l}\text { - Episcleritis and } \\
\text { Scleritis }\end{array}$ & $620(0.60)$ & $293(0.5)$ & 47.26 & \\
\hline & $\begin{array}{l}\text { - Preseptal/Orbital } \\
\text { Cellulitis }\end{array}$ & $547(0.53)$ & $338(0.58)$ & 61.79 & \\
\hline & Total & $\begin{array}{l}63648 \\
(61.68)\end{array}$ & $\begin{array}{l}30627 \\
(52.12)\end{array}$ & 48.12 & \\
\hline \multirow[t]{5}{*}{$\begin{array}{l}\text { Foreign } \\
\text { body/trauma }\end{array}$} & $\begin{array}{l}\text { - Ocular surface foreign } \\
\text { body }\end{array}$ & $\begin{array}{l}24942 \\
(24.18)\end{array}$ & $\begin{array}{l}21155 \\
(36)\end{array}$ & 84.81 & \\
\hline & - Blunt eye trauma & $\begin{array}{l}1142 \\
(1.11)\end{array}$ & $618(1.05)$ & 54.12 & \\
\hline & - Open-globe eye injury & $330(0.32)$ & $151(0.26)$ & 45.75 & \\
\hline & • Eyelid injury & $176(0.17)$ & $147(0.25)$ & 83.52 & \\
\hline & Total & $\begin{array}{l}26590 \\
(25.78)\end{array}$ & $\begin{array}{l}22071 \\
(37.56)\end{array}$ & 83.01 & \\
\hline \multirow[t]{3}{*}{ Allergic } & - Allerjic conjunctivitis & $\begin{array}{l}3891 \\
(3.77)\end{array}$ & $\begin{array}{l}1426 \\
(2.43)\end{array}$ & 36.65 & \\
\hline & - Vernal conjunctivitis & $\begin{array}{l}3284 \\
(3.18)\end{array}$ & $\begin{array}{l}1140 \\
(1.94)\end{array}$ & 34.71 & \\
\hline & Total & $\begin{array}{l}7175 \\
(6.95)\end{array}$ & $\begin{array}{l}2566 \\
(4.37)\end{array}$ & 35.76 & \\
\hline
\end{tabular}

1: Chi-Square test, The Group 2/Group 1 column defines the ratio of diagnoses during the pandemic period to the pre-pandemic period. Especially infectious and allergic diseases decreased by more than $50 \%$ during the pandemic period compared to the pre-pandemic period. 


\begin{tabular}{|c|c|c|c|c|c|}
\hline \multirow[t]{2}{*}{ Diagnosis } & & \multirow{2}{*}{$\begin{array}{l}\text { Group } 1 \\
n,(\%)\end{array}$} & \multirow{2}{*}{$\begin{array}{l}\text { Group } 2 \\
n,(\%)\end{array}$} & \multirow{2}{*}{$\begin{array}{l}\text { Group 2/Group } \\
1(\%)\end{array}$} & \multirow{2}{*}{$\begin{array}{l}\text { p } \\
\text { (group1- }\end{array}$} \\
\hline & & & & & \\
\hline \multirow[t]{7}{*}{ Others } & - Retinal Diseases & $\begin{array}{l}1924 \\
(1.87)\end{array}$ & $\begin{array}{l}1336 \\
(2.27)\end{array}$ & 69.44 & \\
\hline & $\begin{array}{l}\text { - Conjunctival } \\
\text { Hemorrhage }\end{array}$ & $\begin{array}{l}1416 \\
(1.37)\end{array}$ & $638(1.08)$ & 45.06 & \\
\hline & - Glaucoma & $\begin{array}{l}1216 \\
(1.18)\end{array}$ & $738(1.26)$ & 60.69 & \\
\hline & - Vitreous Diseases & $\begin{array}{l}1083 \\
(1.05)\end{array}$ & 699 (1.19) & 64.54 & \\
\hline & - Retinal Detachment & $126(0.12)$ & $88(0.15)$ & 69.84 & \\
\hline & Total & $\begin{array}{l}5765 \\
(5.59)\end{array}$ & $\begin{array}{l}3499 \\
(5.95)\end{array}$ & 60.69 & \\
\hline & Total & $\begin{array}{l}103178 \\
(100)\end{array}$ & $\begin{array}{l}58763 \\
(100)\end{array}$ & & \\
\hline
\end{tabular}

In both the pandemic and pre-pandemic periods, infectious and allergic conjunctivitis were significantly most common in spring; the diagnoses of ocular trauma, foreign bodies on the ocular surface, and stye/chalazion were most common in summer; and the diagnoses of adenoviral and herpetic keratoconjunctivitis were most common in winter. There was no significant difference between seasons for other diagnoses.

Retinal disease, iridocyclitis, and glaucoma were the most common diagnoses after acute conjunctivitis and ocular surface foreign body diagnoses, respectively, in the age group $\geq 65$ years (Figure 2 ).

\section{Discussion}

There was a numerically significant decrease in eye emergency department visits during the pandemic period in all seasons compared to the pre-pandemic period. The reason for this may be the protective measures against coronavirus or that our patients are more cautious about applying to the emergency department. We think that the information announcements of the Turkish Ophthalmology Association are also guiding in this regard to warn our patients and raise awareness so as not to delay the treatment of emergency eye diseases in our country.

It was found that eye emergency department admission rates due to infectious/inflammatory and allergic diseases decreased most significantly during the pandemic period. In a study by Carvalho et al. [18], it 
was reported that approximately $55 \%$ of patients admitted to the eye emergency department had infectious/inflammatory diagnoses. In our study, infectious/inflammatory causes were the most common admission diagnoses (61.6\% and $51.1 \%$, respectively) in both the pre-pandemic and pandemic periods. In our study, the reason for the decrease in infectious and allergic conjunctivitis, and keratitis cases during the pandemic period may be that the decrease in exposure to infectious microorganisms in the external environment and the positive improvements in personal hygiene habits $[11,14,15]$. In view of this result, it would be appropriate to draw attention to this issue by increasing information and educational efforts on personal hygiene in order to protect against these diseases and preserve public health.

In a 1-year prospective study conducted by Henriquez et al. [19] before the pandemic, it was reported that the most common diagnoses for an emergency eye examination in children were infectious conjunctivitis, corneal abrasions, and noninfectious conjunctivitis. In a 1-year prospective study conducted in the prepandemic period, Sen et al [20] reported that children most commonly referred to the emergency room due to allergic and infectious conjunctivitis. In our study, similar to the above studies it was found that children were most frequently admitted to the emergency department for infectious and allergic conjunctivitis, and ocular surface damage due to foreign bodies both before and during the pandemic. Educating parents about preventive measures and raising awareness among school-age children about the prevention and transmission of these diseases can reduce the incidence of these diseases in childhood.

A study by Pellegrini et al [12] found that there was a significant decrease in eye injuries during the pandemic period due to both occupational and non-occupational causes (sports, violence, falls, etc.). Similarly, in our study, there was a significant decrease in blunt and penetrating eye injuries during the pandemic period. The reason for this decrease could be working from home or rotation system during the pandemic period. There are studies in the literature reporting that ocular traumas occur mainly in males and between the ages of 15-45 years [21,22]. In this study, ocular trauma was found to be most common in males and the 17-40 age group for all age groups, both in the first one-year period of the pandemic and in the one year before the pandemic. To prevent people of working age from being exposed to eye trauma, the provision of protective measures by the employer and the observance of their implementation by the employee is of great importance for protection.

In our study, it was observed that there was a significant decrease in the rate of applications from individuals aged 16 years and under and above 65 years of age. This decrease could be due to the transition to distance education in the age group of children and the decline in outdoor activities. In the cases of those above 65 years of age, we assume that stricter closure measures implemented for this age group in our country may be effective in this decrease. In addition, in patients aged 65 years and older, the incidence of sight-threatening diseases such as retinal diseases (retinal vascular diseases. age-related macular degeneration, and other retinopathies. etc.), iridocyclitis, and glaucoma was significantly higher during the pandemic period than in other age groups. As expected in the older age group, the increase in risk for these diseases with age may explain the higher incidence in this age group. 
One of the limitations of our study is its retrospective design. The other limitation is; requests made within the first 10 days by patients who revisit the emergency department are accepted in our country's health system with the same protocol number, but a separate control number is assigned for repeat requests after 10 days. This may have resulted in repetition for some diagnoses in patients who reapplied after 10 days from the first visit. However, due to the large study population, we think that these patients will not affect the overall statistical results. The strongest aspect of our study is that it covers a large number of patients by comparing the first year of the pandemic with the period of one year before the pandemic. Our hospital is the only eye-specific public hospital in Ankara and the surrounding provinces. Unlike other centers that were extremely busy due to other branch patients during the Covid 19 pandemic, our hospital served only ophthalmology patients. Due to the above-mentioned reasons, our hospital has become a center preferred by emergency eye patients and patients are referred from other hospitals. This allowed our study to include a large number of patients. As can be seen from these data, our hospital has taken care to provide health services to all applicants during the pandemic period as a center where outpatient treatment services for ocular emergency patients are successfully carried out.

As a result of this study, it was determined that in the first year of the pandemic, applications to the emergency department of a tertiary eye hospital decreased significantly compared to the pre-pandemic period thanks to the protective measures against coronavirus. In the pediatric age group, both before and during the pandemic the most common presentations were thought to be conjunctivitis and foreign bodies in the eye, and it was thought that there was a need to increase awareness among parents and children of protective measures against these.

We are concerned that the decrease in emergency room admissions during the pandemic period may be due to the fact that ocular symptoms and diseases are neglected by patients due to the risk of contracting Covid-19. We think that patients with risk factors and chronic eye diseases should be aware that they should not neglect eye diseases during this period and should pay attention to eye control visits. Ophthalmologists should also take into account that the decrease in emergency department applications during the pandemic period may lead to intensive patient admissions and they may encounter more complicated diseases during the recovery period. Health-care delivery planning should be carried out considering these situations.

\section{Declarations}

Conflict of interest statement: The authors declare that they have no affiliations with or involvement in any organization or entity with any financial or non-financial interest in the subject matter or materials discussed in this manuscript.

Funding: No funding was received for this research.

This submission has not been published anywhere previously and it is not simultaneously being considered for any other publication. 


\section{Compliance with ethical standards}

Informed consent Since information obtained from the hospital record system was used in the study, informed consent was not obtained.

\section{References}

1. Shemer A, Einan-Lifshitz A, Itah A et al (2021) Ocular involvement in coronavirus disease 2019 (COVID-19): a clinical and molecular analysis. Int Ophthalmol 2:433-440. doi:10.1007/s10792-02001592-1

2. Erdem I (2020) Quarantine and Precaution Policies of Turkey Against Coronavirus (Covid-19). Journal of Turkish Studies. doi:10.7827/TurkishStudies.43703

3. Ministry of Health of Turkey. The Current Covid-19 Situation in Turkey 2021. Available from: https://covid19.saglik.gov.tr/

4. Turkish Ophthalmology Association. Turkish Ophthalmology Association Coronavirus webpage 2020 [cited 2021]. Available from: https://koronavirus.todnet.org/

5. Ahmed TJ, Baig M, Bashir MA et al (2021) Knowledge, attitudes, and perceptions related to telemedicine among young doctors and nursing staff at the King Abdul-Aziz University Hospital Jeddah, KSA. Niger J Clin Pract 4:464-469. doi:10.4103/njcp.njcp_34_20

6. Evin F, Er E, Ata A et al (2020) The Value of Telemedicine for the Follow-up of Patients with New Onset Type 1 Diabetes Mellitus During COVID-19 Pandemic in Turkey: A Report of Eight Cases. J Clin Res Pediatr Endocrinol. doi:10.4274/jcrpe.galenos.2020.2020.0160

7. Jayaram H, Strouthidis NG, Gazzard G (2020) The COVID-19 pandemic will redefine the future delivery of glaucoma care. Eye (Lond) 7:1203-1205. doi:10.1038/s41433-020-0958-1

8. Ferahman S, Dural AC, Aydin H et al., Analysis of general surgery outpatient clinic admissions and operations during COVID-19 pandemic in Turkey: Reactions of 12728 patients (2020) 475-80. doi: 10.4149/BLL_2020_086

9. Erdem B, Gok M, Bostan S (2021) The evolution of the changes in the clinical course: a multicenter survey-related impression of the ophthalmologists at the peak of the COVID-19 pandemic in Turkey. Int Ophthalmol 4:1261-1269. doi:10.1007/s10792-020-01681-1

10. Lai THT, Tang EWH, Li KKW, The Implications of COVID-19 to Ophthalmology, Adv Exp Med Biol. (2021) 637-55. doi: 10.1007/978-3-030-63761-3_35

11. Kalkan Uğurlu DH, Nemutlu Y, Kurd E O, Assessment of knowledge and attitude of social handwashing in Turkey population during COVID-19 pandemic, J Contemp Med 2020; 10(4): 617624. (2020). doi: $10.16899 / \mathrm{jcm} .745349$

12. Pellegrini M, Roda M, Di Geronimo N et al (2020) Changing trends of ocular trauma in the time of COVID-19 pandemic. Eye (Lond) 7:1248-1250. doi:10.1038/s41433-020-0933-x 
13. Rohl A, Kalhorn A, Singh J et al (2020) Decreased retinal detachments during a COVID-19 lockdown period in Colorado. Acta Ophthalmol. doi:10.1111/aos.14570

14. Teslya A, Pham TM, Godijk NG et al (2020) Impact of self-imposed prevention measures and shortterm government-imposed social distancing on mitigating and delaying a COVID-19 epidemic: A modelling study. PLoS Med 7:e1003166. doi:10.1371/journal.pmed.1003166

15. Shiraly R, Shayan Z, McLaws ML (2020) Face touching in the time of COVID-19 in Shiraz, Iran. Am J Infect Control 12:1559-1561. doi:10.1016/j.ajic.2020.08.009

16. Garcia-Ayuso D, Escamez-Torrecilla M, Galindo-Romero $C$ et al., Influence of the COVID-19 pandemic on contact lens wear in Spain, Cont Lens Anterior Eye. (2020) 101351. doi:

10.1016/j.clae.2020.07.002

17. Morgan PB, Contact lens wear during the COVID-19 pandemic, Cont Lens Anterior Eye. 3 (2020) 213-. doi: 10.1016/j.clae.2020.04.005

18. Carvalho Rde S, Jose NK, Ophthalmology emergency room at the University of Sao Paulo General Hospital: a tertiary hospital providing primary and secondary level care, Clinics (Sao Paulo). 3 (2007) 301-8. doi: 10.1590/s1807-59322007000300015

19. Henríquez R, Noval S, Zafra B et al., Ocular Emergencies in Children: Demographics, Origin, Symptoms, and Most Frequent Diagnoses, Journal of Ophthalmology. (2020) 6820454. doi:10.1155/2020/6820454

20. Sen E, Celik S, Inanc M et al (2018) Seasonal distribution of ocular conditions treated the emergency room: a 1-year prospective study. Arq Bras Oftalmol 2:116-119. doi:10.5935/00042749.20180026

21. Galindo-Ferreiro A, Sanchez-Tocino H, Varela-Conde $Y$ et al (2021) Ocular emergencies presenting to an emergency department in Central Spain from 2013 to 2018. Eur J Ophthalmol 2:748-753. doi:10.1177/1120672119896420

22. Selda ÇELIKDÜLGER, Kadriye Ufuk ELGiN, E. ŞEN, The Epidemiological Evaluation of Ocular Penetrating or Blunt Trauma Cases Applied to Emergency Room of an Eye Hospital, Clinical and Experimental Ocular Trauma and Infection. (2020)

\section{Figures}




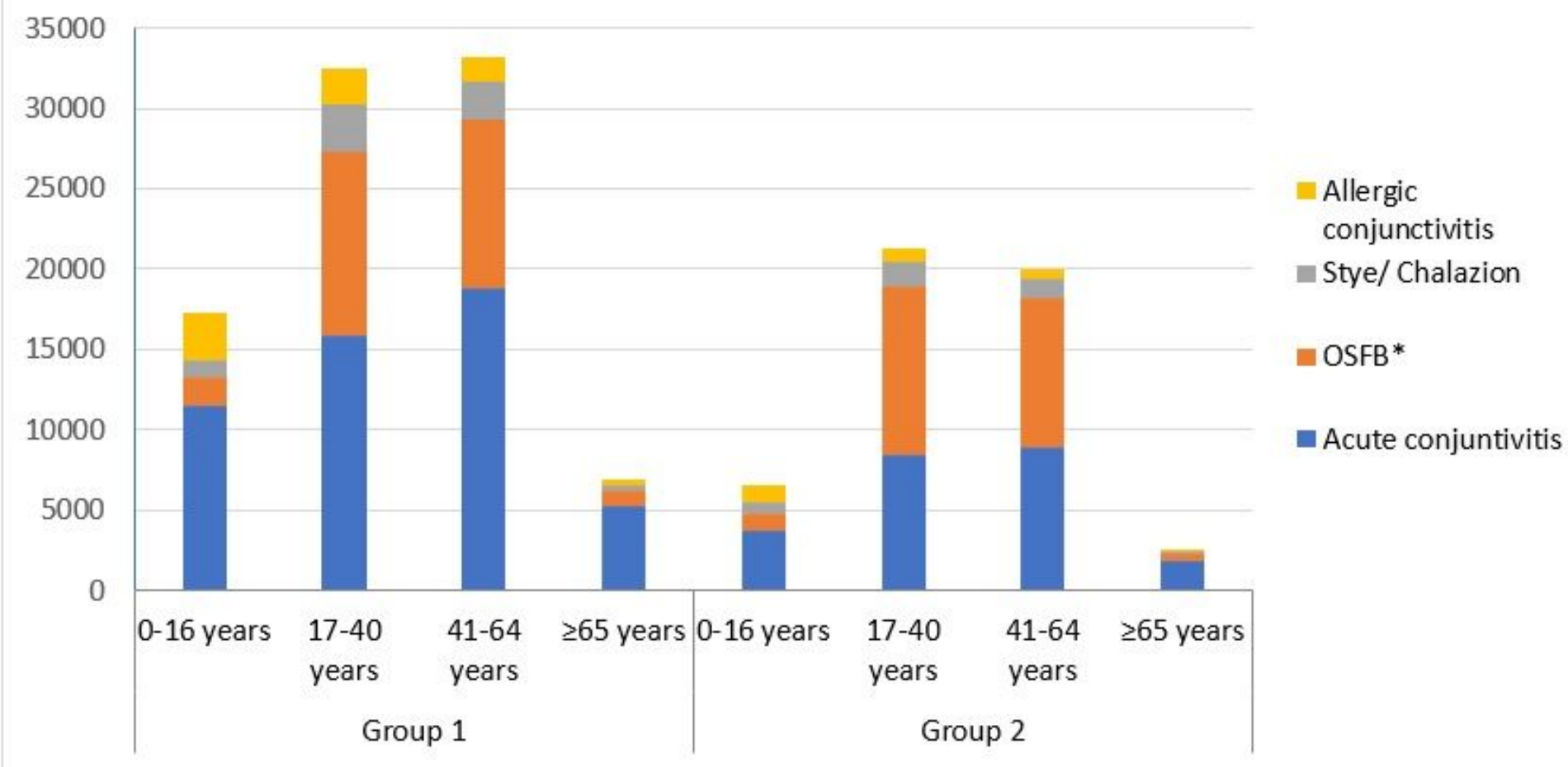

* Ocular surface foreign body

\section{Figure 1}

The most frequent diagnosis distribution according to patient age groups in Group 1 and 2. 


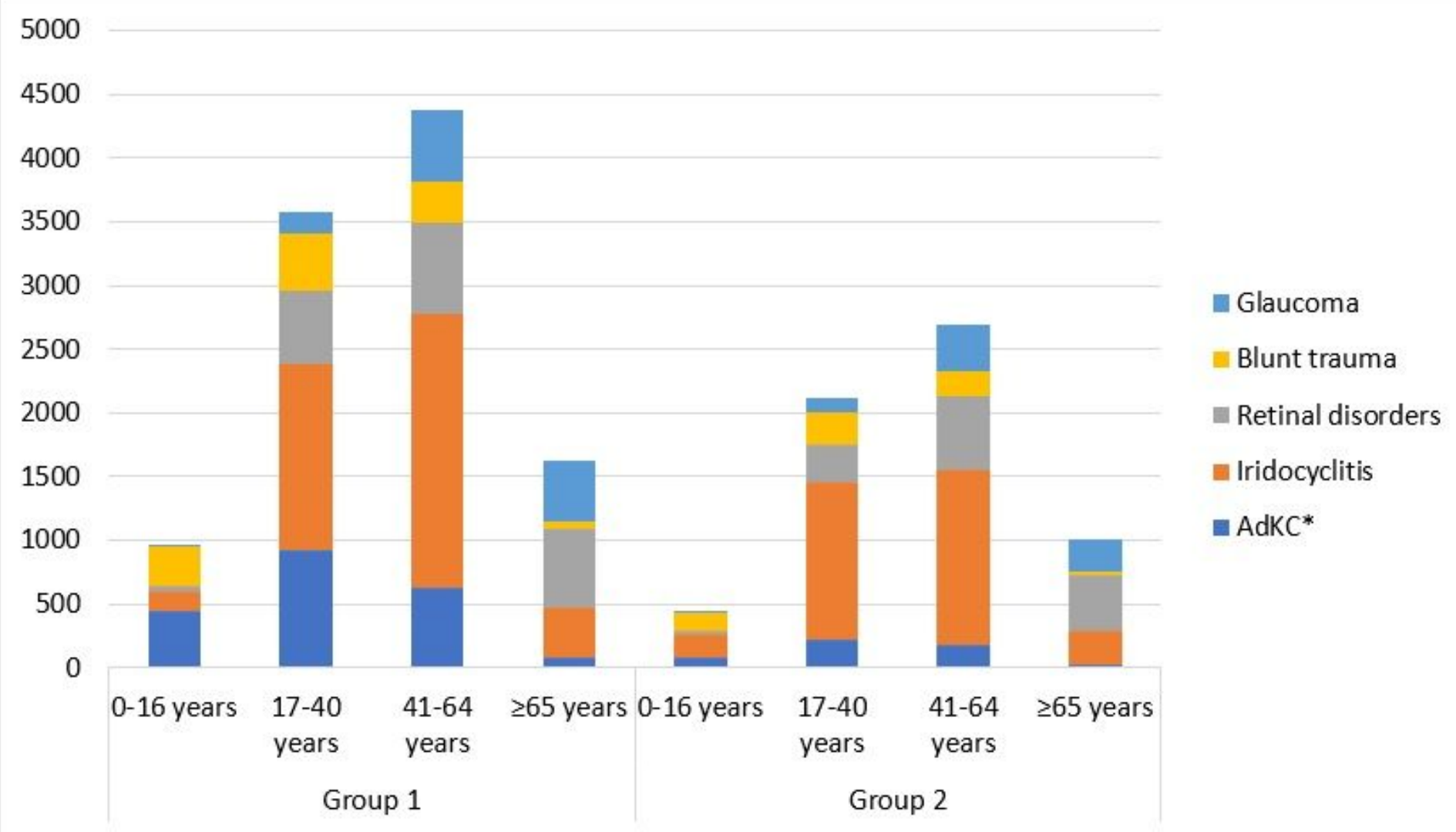

*Adenoviral keratoconjunctivitis

Figure 2

Less frequent diagnoses according to patient age groups in Group 1 and 2. 